\title{
MS113.P01
}

\section{Growing crystals: Teacher support in the use of science labs}

$\underline{\text { Adriana Serquis }}^{1}$, Ariel Pullao ${ }^{2}$, Priscila Berger ${ }^{2}$, Sasha E. Dubois ${ }^{2}$, Carla Brachetti ${ }^{2}$, Nayla T. Schroh ${ }^{2}$, Verónica Flores $^{2}$, Nelly $^{2}$ Maglianos $^{2}$, Paola Cabrera ${ }^{2}$, Andrés Raviolo ${ }^{2}$

${ }^{1}$ Materials Characterization Department - CNEA-CONICET, Bariloche, Argentina, 2 Universidad Nacional de Río Negro (UNRN), Bariloche, Argentina

E-mail: aserquis@cab.cnea.gov.ar

The limited presence of the natural sciences in school, and the non-systematic teaching of its contents, is part of a school tradition in many of the primary educational institutions in Argentina.

During 2015 Primary schools in the city of Bariloche received laboratory materials from the Natural Science for All Plan at the Elementary level. In most schools this material is not used. This is due, to a large extent, to some inertia and insecurity in teachers. Therefore, the Chemistry teacher training career of the University of Rio Negro (UNRN) created the program "Teacher support in the use of science laboratory in primary schools in the city of Bariloche"

The objective of this program is that students of the last years of the Chemistry teacher training career accompany teachers of public elementary schools in the planning and execution of experimental activities, in particular teachers of the schools of popular sectors of the city. These activities use the laboratory materials received to show how crystals grow.

Since the IYCr, the Argentine Association of Crystallography (AACr) has worked in a permanently in the training of teachers of the area. The graduate students that form this program received training through their participation in a course on the topic of crystal growth, in cooperation with the Argentine Association of Crystallography.

Experimental activities were carried out on 18 classrooms in 11 elementary schools, and were attended by more than 400 students. Fundamentally, experimental crystal growth activities were performed with: sugar crystals (in brochette sticks: sugar sticks), borax (egg shell geodes), copper sulphate (figures in pipe wires), salt (columns of salt) and crystals of alum.

Student participation was focused on the promotion of scientific procedures and competences such as: systematic observation, hypothesis formulation, experimental design, variable identification and control, data recording and conclusion extraction and modeling. The implementation of all these procedures with elementary students were feasible with the help of the teacher and, in this case, the UNRN students.

The intervention of the university students was a positive stimulus for the concrete realization of the activities and, in addition, contributed to: (a) improving the didactic sequences, (b) incorporating the use of videos and (c) with the naked eye and with the use of microscopes, common and digital (USB microscopes). It also caused a remarkable motivation and participation of the elementary school students.

Although the demand that gives rise to this program is very broad, and exceeds its possibilities, a step has been taken in the right way. The interest and participation in experimental activities and in the use of the laboratory, both of teachers and students of elementary school, and in several cases of the school management team have been encouraged. From the primary teacher appraisal of the experience an increased confidence and knowledge appear as learning asset, encouraging teachers to continue applying lab activities in their usual practice.
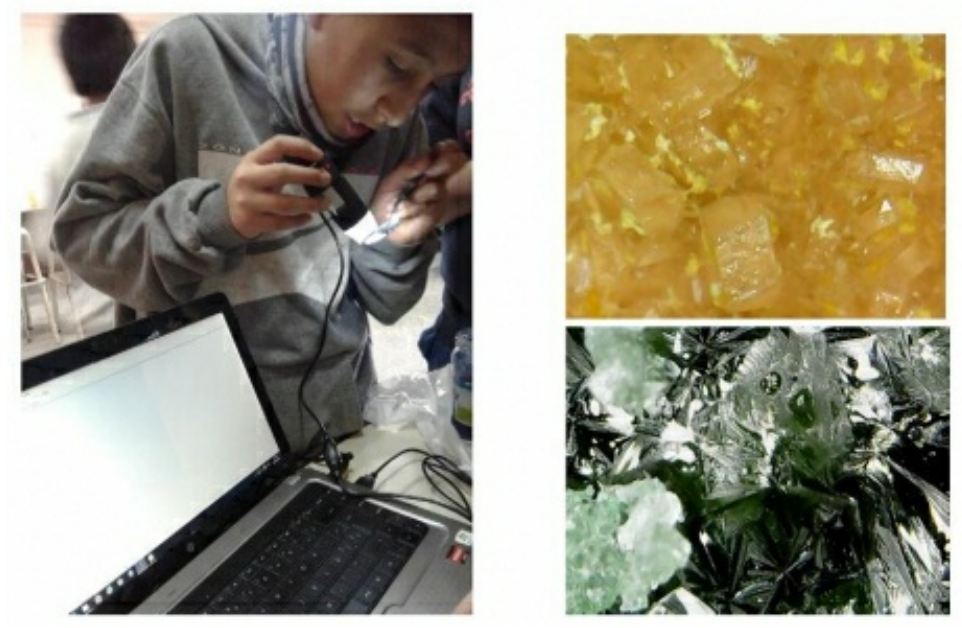

Keywords: growing crystals, primary schools, teacher training career 